\title{
USAGE OF MICROSCOPIC METHODS IN ANALYSIS OF NON-CONFORMING NICKEL ALLOY PRODUCTS
}

\author{
Sylvia Kusmierczak ${ }^{1}$, Natasa Naprstkova ${ }^{1}$, Milos Mician ${ }^{2}$ \\ ${ }^{1}$ J. E. Purkyne University in Usti nad Labem, Czech Republic; \\ ${ }^{2}$ University of Zilina, Slovakia \\ kusmierczak@fvtm.ujep.cz,natasa.naprstkova@ujep.cz,milos.mician@fstroj.uniza.sk
}

\begin{abstract}
The process of creating products with the required utility properties is a multi-stage process determined by a number of factors that determine the resulting quality. Today, given the pressure on the economic side of production, companies have limited input control to the minimum possible. Spectral analysis, material hardness evaluation, or layer thickness control are most often performed. They carry out other analyses in companies sporadically. Common input analyses often do not reveal the actual state of the microstructure such as the presence of undesirable phases, their size, phase distribution, their heterogeneity, etc. These factors affect the weldability and cold formability of the workpiece, and consequently affect the resulting product quality and product life. In the case of bellows production, the input semi-finished products are subject to requirements in terms of technological division of production, which includes input cutting, welding, forming and calibration of the finished product. Even in nickel alloys, the more chemically and structurally complicated the material, the lower its formability. An important factor influencing the formability of these alloys is the occurrence of inclusions. The negative influence of inclusions on cold formability depends on the chemical composition, mechanical properties, their morphology, frequency and distribution in the base matrix. In terms of weldability, nickel alloys are very well weldable. Their weldability is dependent on chemical purity, especially sulphur, carbon and chromium content. The influence of other alloying elements on the weldability of nickel alloys is minimal. Only precipitation-hardened alloys are more difficult to weld. Almost all welding methods as with steel can be used. The paper presents the use of microscopic methods for detecting the causes of non-conforming bellows from nickel alloys.
\end{abstract}

Keywords: bellow, nickel alloys, microscopy, fractography.

\section{Introduction}

Bellows is defined according to CSN EN ISO 14917 as a resilient element consisting of one or more undulations and unformed ends. Its task is to compensate for various types of movements in piping systems. Connecting the bellows to the required connection type (e.g. pipe, flange) creates a compensator. The materials for the production of metal bellows can be austenitic stainless and heat resistant steels, nickel stainless and heat resistant alloys [1;2].

Bellows production technology is a multi-stage process that includes technologies such as shearing, forming, welding and dimensional calibration. This is followed by testing, which is aimed at checking the required dimensions, wave geometry, surface quality of the bellows material, respectively, intrusion deformations. All of these are the steps needed to achieve a quality product while achieving economically profitable profits.

A number of internal and external factors affecting the technological properties of the blank can cause a bellows quality problem [3]. The formability and weldability of bellows in terms of internal factors are influenced in particular by the chemical composition of the stock, the microstructure, the grain size, the inclusions, their type, size, distribution, microstructure fraction and arrangement. Technological parameters of individual operations can be considered as external factors, which in the case of manufacturing companies are repeatable and thus can be considered as constant. The problem arises, when the repeatability is not maintained even for the input semi-finished products, which is currently a relatively frequent case, which are supplied to the production by sellers from several manufacturers. A comprehensive approach $[3 ; 4]$ to the assessment of external and internal factors leads to the identification of critical points in the process. Critical points are used to set limit values for individual factors in order to ensure quality at the cost of the lowest financial burden on the production process. Nowadays, in view of the great competition in technical production, companies are led to ensure that the initial inspection of the semi-finished product is carried out at minimal cost. That is why it is possible in companies to check the chemical composition of semi-finished products using portable devices. Static devices often already need special sample treatments, which in turn leads to increased economic requirements for this control. Another frequent method for checking mechanical properties, which is relatively inexpensive, is the hardness evaluation using portable devices or NDT 
methods. However, technical practice often raises product quality problems where light and electron microscopy need to be involved in the inspection process [2-5]. Light microscopy is often represented in production plants as part of the output control, which cannot be said about electron microscopy. Electron microscopy follows light microscopy and develops it especially in the field of chemical microanalyses and phase analyses. Other applications include the determination of fracture surface morphology, phase distribution and arrangement within the fracture surface. This method can be successfully used for reverse analysis, where the fracture surface morphology helps to deduce not only the cause of the component failure, but also gives answers to the change of the semi-product behavior during the technological process [6-8].

The aim of the paper is to show the use of microscopic methods for the detection of the causes of the non-conforming bellows formation from the selected nickel alloy.

\section{Description of the problem}

The bellows consists of six layers, with a single layer thickness of $0.5 \mathrm{~mm}$. The inner and outer layers are made of nickel alloy 2.4858 according to VdTÜV - WB 432/1 and intermediate layers of austenitic stainless steel ČSN EN 10088 - 1.4541. Localized cracks have a dimension 5-15 mm, see Fig. 1. They were formed during the metal bellows forming process, namely at the stage of expanding the diameter to the desired value. Cracks always occurred on the inside of the bellows at the top of the wave and in the HAZ of the weld joint. The crack direction is perpendicular to the direction of tool action.

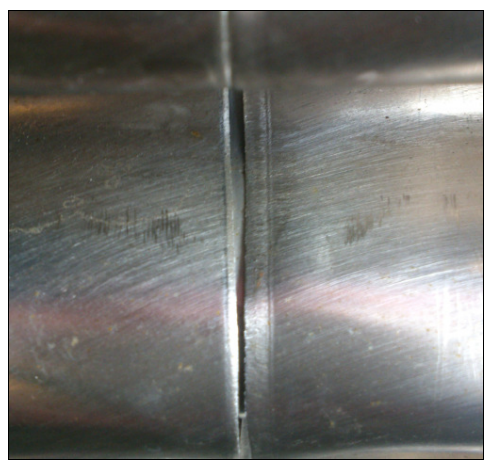

Fig. 1. Crack in HAZ

Specimen description: to analyze the causes of the bellows cracking of the compensator, samples were taken from sheets and marked OK and NOK.

- OK sample - taken from the sheet in the form of a coil, no cracks occurred during production,

- NOK sample - taken from sheet metal plate, cracks already localized at bellows height (3032) $\mathrm{mm}$.

\section{Materials and methods}

\section{Analysis of chemical composition of semi-finished technical object}

As a first step in the search for causes of cracking, the chemical composition of the material samples was analyzed. The chemical composition of the material according to the standard is given in Table 1.

Table 1

Chemical composition (wt \%) of material 2.4858 according to VdTÜV-Werkstoffblatt 432/1

\begin{tabular}{|c|c|c|c|c|c|c|c|c|c|c|c|c|c|}
\hline & $\mathbf{N i}$ & $\mathbf{C r}$ & $\mathbf{C u}$ & $\mathbf{M o}$ & $\mathbf{T i}$ & $\mathbf{A l}$ & $\mathbf{M n}$ & $\mathbf{S i}$ & $\mathbf{C}$ & $\mathbf{P}$ & $\mathbf{S}$ & $\mathbf{F e}$ & $\mathbf{C o}$ \\
\cline { 1 - 7 } Min. & 38.00 & 19.50 & 1.50 & 2.50 & 0.60 & - & - & - & - & - & - & \multirow{2}{*}{ rest } & under \\
\cline { 1 - 2 } Max. & 46.00 & 23.50 & 3.00 & 3.50 & 1.20 & 0.20 & 1.00 & 0.50 & 0.025 & 0.020 & 0.010 & & \\
\hline
\end{tabular}

The chemical composition of the samples was analysed using an X-MET3000TX spectrometer. The instrument does not detect the chemical elements $\mathrm{Al}, \mathrm{Si}, \mathrm{C}, \mathrm{P}$ and $\mathrm{S}$ and corrects the measured values towards $100 \%$. The measurement was performed 5 times. Tab. 2 shows the identified chemical elements, the arithmetic mean weight percent $\overline{\mathrm{w}} \mathrm{\%}$. 
Chemical composition of samples

\begin{tabular}{|c|c|c|c|c|c|c|c|c|c|c|c|}
\hline Sample & Value, \% & Ti & Cr & Mn & Fe & Co & Ni & Cu & Nb & Mo & W \\
\hline OK & $\bar{w}$ & 0.34 & 21.2 & 0.21 & 32.1 & 0 & 39.9 & 2.3 & 0 & 3.3 & 0.05 \\
\hline NOK & $\bar{w}$ & 0.47 & 21.5 & 0.25 & 31.5 & 0.08 & 41.6 & 1.63 & 0.09 & 2.93 & 0.06 \\
\hline
\end{tabular}

Chemical composition of samples \% of individual chemical elements is in standardized values. The exception is wt. \%, which is below the limit of $0.6 \%$ for all samples examined. Tungsten occurs in all samples examined, although its wt. \% is not defined in VdTÜV-WB 432/1.

\section{Static tensile test according to CSN EN ISO 6892-1}

The next step of the solution of the problem is the static tensile test, which was carried out on the Inspekt 100 test equipment in accordance with the standard CSN EN ISO 6892-1. 5 pieces of test specimens in the longitudinal direction with the rolling direction (marked with the symbol II) and 5 pieces of test specimens in the direction perpendicular to the rolling direction (marked with the symbol $\perp$ ) were made of each sheet examined. The values obtained are given in Table 3 .

\section{Measurement results according to ČSN EN ISO 6892-1, average measured values}

\begin{tabular}{|c|c|c|c|c|c|}
\hline \multicolumn{2}{|c|}{ Sample } & Rm, MPa & $\mathbf{R} \mathbf{p}_{0.2}, \mathbf{M P a}$ & $\mathbf{A}_{80}, \%$ & $\mathbf{R p}_{0.2} / \mathbf{R m}$ \\
\hline \multicolumn{2}{|c|}{ OK \| } & 665 & 292 & 45 & 0.4 \\
\hline \multicolumn{2}{|c|}{$\mathrm{OK} \perp$} & 663 & 294 & 49 & 0.4 \\
\hline \multicolumn{2}{|c|}{ NOK $\|$} & 717 & 364 & 39 & 0.5 \\
\hline \multicolumn{2}{|c|}{$\mathrm{NOK} \perp$} & 685 & 381 & 45 & 0.6 \\
\hline \multirow{2}{*}{$\begin{array}{l}\text { VdTÜV- } \\
\text { W432/1 }\end{array}$} & min. & 550 & 235 & 30 & 0.4 \\
\hline & $\max$. & 750 & - & - & 0.3 \\
\hline
\end{tabular}

All measured values correspond to the standard of 2.4858 nickel alloy according to VdTÜVWerkstoffblatt 432/1.

\section{Microscopic analysis using optical microscopy}

The determination of the content of non-metallic inclusions was carried out according to the standard CSN ISO 4967 - method A, on longitudinal sections of the examined samples. Non-metallic inclusions have been identified, Table 4. The table is supplemented with an index number that expresses the dimensions and frequency of non-metallic inclusions.

Table 4

Determination of content of non-metallic inclusions according to CSN ISO 4967

\begin{tabular}{|c|c|c|c|c|c|c|c|c|c|}
\hline \multirow{3}{*}{ Sample } & \multicolumn{9}{|c|}{ Inclusion type } \\
\cline { 2 - 11 } & \multicolumn{2}{|c|}{$\mathbf{A}$} & \multicolumn{2}{|c|}{ B } & \multicolumn{2}{|c|}{ C } & \multicolumn{2}{|c|}{ D } & DS \\
\cline { 2 - 11 } & fine & coarse & fine & coarse & fine & coarse & fine & coarse & \\
\hline OK II & - & - & - & - & - & - & 1 & - & - \\
\hline NOK II & - & - & 0.5 & - & - & - & - & 1 & - \\
\hline
\end{tabular}

Non-metallic inclusions of Group B (aluminate type) and D (globular oxide type) have been identified. Group B non-metallic inclusions are non-deformable, numerous, sharp, low elongation ratios, aligned in the direction of deformation, black or bluish (at least three). Group D non-metallic inclusions are non-deformable, sharp or circular, low elongation ratio, randomly distributed, black or bluish coloured, Fig. 2. The sample NOK II contains line distributed fine inclusions of type B and randomly distributed coarse inclusions of type D. In addition, both types of inclusions are concentrated in a small spot with a diameter of $20 \mu \mathrm{m}$.

Microscopic analysis and micrographic determination of the grain size was performed according to CSN EN ISO 643 method 6.3, on longitudinal and transverse sections of OK, NOK samples, Fig. 3.

It has been found that the grain on the longitudinal and transverse sections is equiaxed, not deformed in the predominant forming direction. The microstructures of the base material are 
comparable in both directions. The microstructure of the base material consists of a single-phase austenitic grain microstructure. Excluded dispersion particles that differ in size and distribution are visible in the images. The nature of the dispersed particles corresponds to the non-metallic inclusions identified.

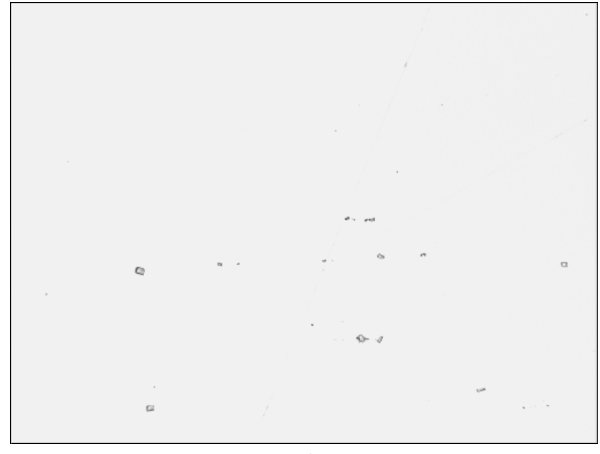

a) Sample OK II

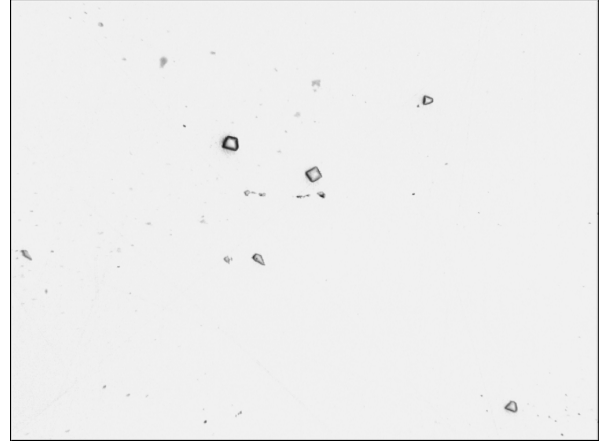

b) Sample NOK II

Fig. 2. Size and distribution of inclusions, mag. $200 \mathrm{x}$, not etched

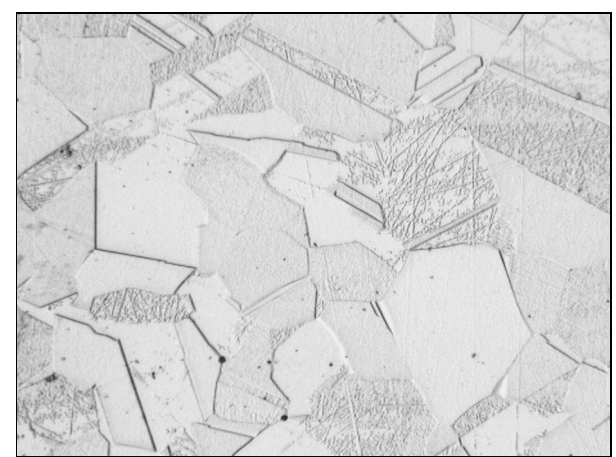

a) Sample OK II

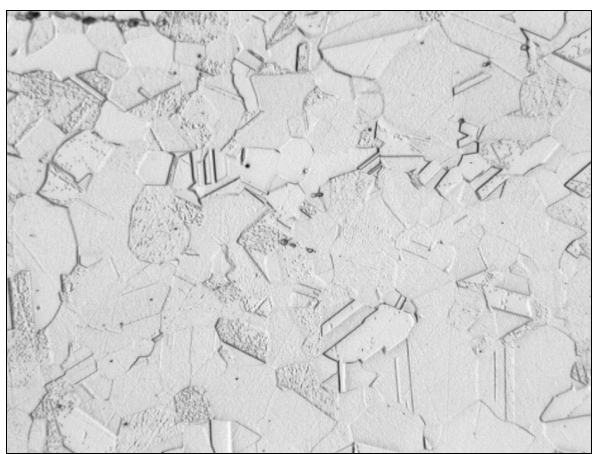

b) Sample NOK II

Fig. 3. Microstructure, mag. 500x, etched $\mathrm{HNO}_{3}+\mathrm{H}_{3} \mathrm{PO}_{4}$

\section{Microstructure analysis of the weld joint}

As the analysed technical object undergoes the welding process in addition to the forming technology, and the cracks occurred in the area of the weld joint, the next step will be to analyse the microstructure of the weld joints. The microstructure analysis of welded joints was performed by means of the light microscope Olympus PME3 according to CSN EN ISO 17639 on cross sections through the weld in examined samples OK, NOK after etching by etching with Ellit $\mathrm{HNO}_{3}+\mathrm{H}_{3} \mathrm{PO}_{4}$ etching. No defects of microstructure were detected in the welded joints according to the standards CSN EN ISO 6520-1 and ČSN EN ISO 5817.4 is a representative of the weld metal microstructure.

The evaluation of the microstructure revealed that the NOK sample differs from the OK samples by the finer grain of the weld metal and base material and the distinct coarse grain band in the HAZ before of the melt line, Fig. 4.

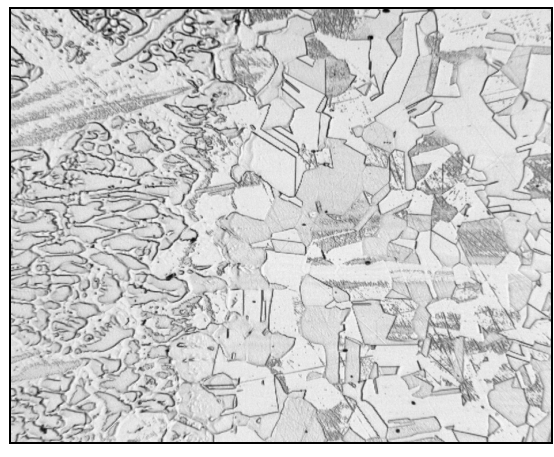

a) Sample OK

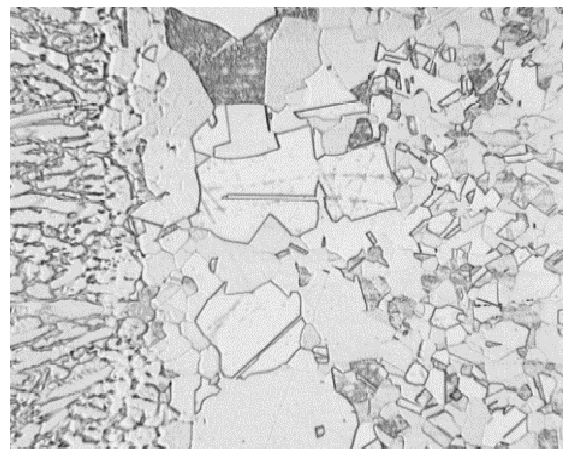

b) Sample NOK

Fig. 4. Microstructure, HAZ, mag. 200 x, etched 


\section{Electron microscopic analysis}

Fractographic analysis was performed to evaluate the fracture surface using a Tescan Vega 3 electron scanning microscope. Fracture surfaces were obtained from samples for static tensile testing.

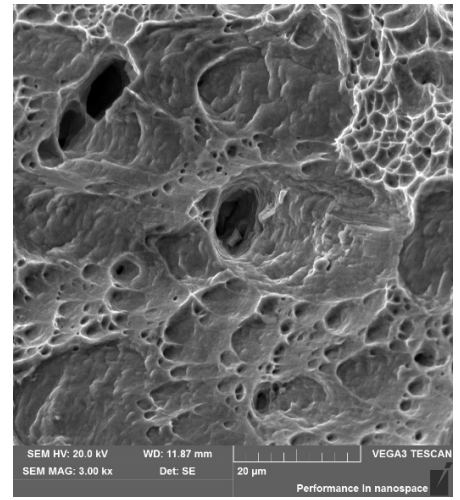

a) Sample OK

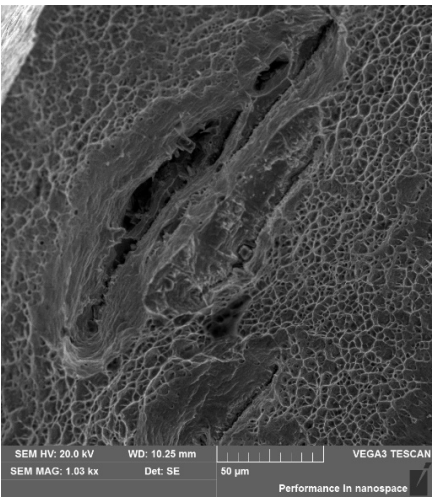

b) Sample NOK, heterogeneity

Fig. 5. Fracture surface morphology

Fractography analysis of the fracture surface of the OK test specimen (Fig. 5a) revealed a ductile failure with typical pitting morphology over the entire fracture surface. The ductile pittings are unevenly distributed and have different depths and sizes.

Fractography analysis of the NOK fracture surface (Fig. 5b) revealed a fine pitting morphology typical for ductile failure over the entire fracture surface. Compared to the OK sample, pittings of ductile failure are more frequent, more evenly distributed, with lower relief. In some places there is a break of cohesion (50-50) $\mu \mathrm{m}$. This region contains a number of sharp-edged particles. These are darker particles in the light matrix (2-10) $\mu \mathrm{m}$ (Fig. 6a), which show a linearity in the rolling direction and incoherence of the interfacial interface. The apparent fragile nature of the particles and their line distribution correspond to the occurrence of cracks initiated in the fracture surface. The results are documented in Fig. 6. The analysis clearly shows the presence of titanium and nitrogen in the particles. These are therefore titanium nitrides.

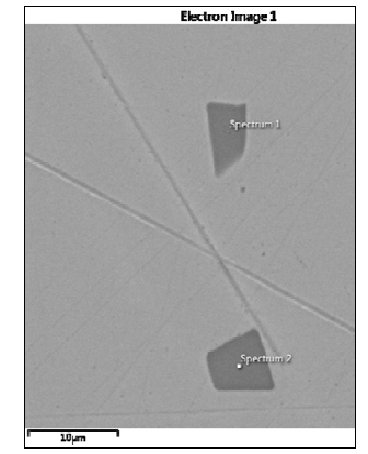

a) sharp edge inclusions

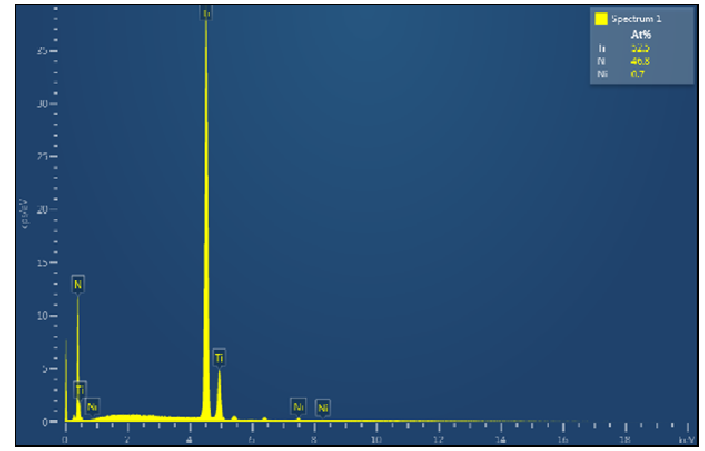

b) results of point EDX analysis

Fig. 6. Sample NOK, point EDX analysis

\section{Discussion}

Based on the performed analyses, it was found that the heterogeneous phases in the matrix of the analysed workpiece are based on titanium nitrides. The presence of $\mathrm{TiN}$ in the microstructure of the 2.4858 nickel alloy can be explained by the presence of $\mathrm{Ti}$ as the alloy stabilizing element. Due to the high affinity of $\mathrm{Ti}$ to $\mathrm{N}$, isomorphic TiN is produced, which is characterized by high hardness, brittleness and high temperature stability. This type of inclusions naturally occurs in nickel alloy 2.4858. However, their morphology and distribution in the matrix are important. Line-excluded inclusions increase the anisotropy of mechanical properties and decrease the plastic characteristics. They cause stress concentrations near them. As a result, there is the change cohesiveness and fracture of the material can occur even under low external loads. The size and distribution of TiN inclusions in the matrix of the NOK sample are essential. On the basis of performed analyses, it can be stated that 
their presence is caused by metallurgical process of production of semi-finished product. In response to problems with the occurrence of bulky inclusions of this type, the addition of Co, which reduces the solubility of Ti in nickel alloys, could be in the metallurgical process of producing the alloy.

\section{Conclusions}

On the basis of the results of the analyses, it is important to point out that initial control of the chemical composition is often not sufficient to maintain adequate product quality. The chemical composition may be in accordance with the stock material standard, but the resulting quality of the finished product is also affected by the microstructure and phase it contains. These significantly affect the technological properties and thus the entire product creation process.

Large manufacturing companies often have facilities to check the chemical composition of the stock material, basic mechanical properties, and less frequently, metallographic preparation equipment and light microscopes. Electron microscopy, with regard to both input and operating costs, is not a common concern. And this evaluation method gives a clear answer to changes in the behaviour of semi-finished products from input to final product inspection. The use of electron microscopy is therefore an effective tool for solving the resulting product quality.

\section{Acknowledgements}

This contribution came from support of the project SG $48207152023-4801$ and U21 at FME UJEP.

\section{References}

[1] Davis. J. R. ASM Specialty Handbook: Nickel, Cobalt, and Their Alloys, 1st edition, ASM International, 2000. Ohio-USA.

[2] Adnyana, D. N. Stress-Corrosion Cracking in a Nickel-Base Alloy Pre-Heater Expansion Bellows. Majalah Metalurgi, vol. 14, 2014, pp. 235-244.

[3] Ren, H. R., Guo, L., Guo, Z. C. Effects of Annealing Temperature on the Microstructure and Mechanical Properties of Electrodeposited Ni-Fe Alloy Foils, High Temp. Mater. Proc., 2017; 36(3), pp. 223-232.

[4] Kusmierczak S., Majzner T. Comprehensive approach to evaluation of degradation in chosen parts of energy equipment. Engineering for Rural Development, 16, pp. 673-679.

[5] Naprstkova N., Cais J., Kraus P., Van T.N. Tool wear evaluation of selected inserts after turning by electron microscopy. Manufacturing Technology, vol. 16 (5), 2016, pp. 1068-1073.

[6] Naprstkova N., Kraus P., Stancekova D. Calcium and its using for modification of $\mathrm{AlSi}_{7} \mathrm{Mg}_{0.3}$ alloy from view of final microstructure and hardness.vol. Engineering for Rural Development, vol. 17, 2018, pp. 2003-2008.

[7] Ryniewicz A. M., Bojko L., Identification of the Cause of the Stem Neck Fracture in the Hip Joint Endoprosthesis. Int. J. of Applied Mechanics and Engineering, 2018, vol.23, No.1, pp. 223-234.

[8] Belan J., Kucharikova L., Mazur M., Tillova E., Chalupova M. Fatigue Characteristics of Materials used in Transport Industry Applications. CzOTO 2019, volume 1, issue 1, pp. 810-818. 